\title{
Effect of Peak Current on the Performance of WEDM
}

\author{
Rajeev Kumar ${ }^{1}$ \\ ${ }^{I}$ (Mechanical Engineering Department, MMU Sadopur, India)
}

\begin{abstract}
WEDM process is used extensively where the conventional machining process shows their limitations. Wire Electrical Discharge Machining is used to manufacture geometrically intricate shapes with higher accuracy and better surface finish. In the present study, the performance parameters i.e. cutting speed and surface roughness were investigated. The experiments were conducted under the constant cutting parameters of $T_{O N}, T_{O F F}, W_{P}, W_{F}, W_{T}, S_{V}$. In the present study, brass wire having diameter $0.25 \mathrm{~mm}$ was used as wire electrode. The brass wire was operated on the D3 work piece material having thickness of $20 \mathrm{~mm}$. During the experimentation, it had been found that the cutting speed and surface roughness increases with increase in peak current. Scanning Electron Microscopy (SEM) images revealed the surface roughness of work piece (after machining).
\end{abstract}

Keywords - wire cut EDM, brass wire, cutting speed, surface roughness, scanning electron microscopy.

\section{INTRODUCTION}

WEDM is a modified electro-discharge machining operation where a NC-controlled travelling wire is used to generate the work-piece geometry. WEDM is basically an adaptation of the EDM process, which can be used for cutting highly complex two and three-dimensional shapes with better surface finish performance.[1] Figure 1 shows the basic operation of WEDM operation. It is a relatively new process and its applications have grown rapidly particularly in the tool making field. WEDM is a technology, which provides high rate of cutting and high-precision operation to realize enhance productivity and improved accuracy. In WEDM, dielectric is used in working space i.e gap space between wire electrode and workpiece to allow cooling action. It also allows flushing out of debris or the resolidified eroded particles from the gap. Effective flushing is required, otherwise eroded particle in the gap will cause undesirable craters in the wire and workpiece material.

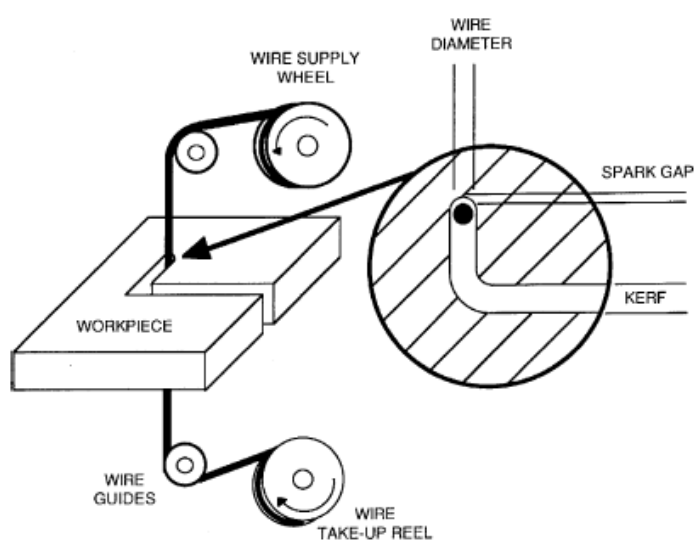

Fig.1. Detail of WEDM operation [2]

\section{LITERATURE REVIEW}

Ebeid et al. (2003) had proposed a knowledge based system for the selection of an optimal setting of process parameters. It also helps in diagnosing the machining conditions particularly for WEDM. In this study, sample outcomes for Al 6061 and alloy steel 2417 were presented in the form of particular charts. These charts helps WEDM users to improve the performance of the WEDM process. Saha et al. (2004) developed a new approach based on finite element modeling which leads towards optimization procedures for analyzing the process of WEDM. The outcomes of the modeling and optimization concluded that the non uniform heating is a 
most significant factor which may affects the thermal strains. Tosun et al. (2004) had analyzed the effect of machining parameters on the performance parameters i.e. kerf width and material removal rate (MRR). They used ANOVA method as optimization tool. During the investigation, they had concluded that the open circuit voltage and pulse duration are most effective parameters, whereas flushing pressure and wire feeding rate are less effective factors. Lin and Lin (2005) had worked in the field of optimization of EDM process. They had suggested a new approach based on the orthogonal array with the grey relational analysis. They had optimized the process parameters viz. duty factor, servo voltage, flow rate of dielectric, discharge current, pulse on time and work piece polarity against the performance parameters viz. surface roughness, MRR (material removal rate) and EWR (electrode wear ratio). Sarkar et al. (2005) had performed investigation (experimental based) on single pass cutting of wire EDM of $\gamma$-TiAl alloy. The additive modeling approach was used to modeled the whole process. The Pareto optimization algorithm was used as optimization tool. The wire-EDM process was optimized under single constraint as well as multi-constraint condition. Twenty pareto solutions (optimal one) were searched out from the set of all 243 outputs. During the study, it was concluded that the performance parameters i.e surface roughness and dimensional deviation are independent on the pulse off time. Mahapatra et al. (2007) had used the Taguchi method for optimization of WEDM process. The zinc coated copper wire was used as tool electrode and D2 tool steel (with thickness of $10 \mathrm{~mm}$ ) was used as work material. During this study, the effect of different process parameters i.e. peak current, pulse duration, frequency of pulse, wire feed rate, flow rate of dielectric and wire tension on performance parameters i.e. MRR, surface finish and cutting width was analyzed. They also used Taguchi method for optimizing the process parameters. Data \& Mahapatra (2010) had also worked in the field of WEDM. They used D2 material as work material and zinc coated copper wire $(0.25 \mathrm{~mm}$ diameter) was used as tool electrode. They suggested and derived mathematical models (quadratic) to represent the behavior of WEDM process. They had varied six different process parameters i.e. discharge current, pulse duration, frequency of pulse, feed rate of wire, flow rate of dielectric and wire tension in three different levels. They varied these process parameters against the three performance parameters i.e. MRR, surface roughness and kerf width. After the prediction of data, they represents the effect of the parameters on selected responses by graphical representation. They also used GreyTaguchi technique for optimization of input parameters. Kumar et al (2012) had presented a review study which explore the different areas related to WEDM on which the recent study had been going on. The presented review basically highlights the work of various researchers in the field of analysis and optimization of WEDM process. Joshi et al (2014) had analyzed the effect of different input parameters viz. pulse on time, pulse off time, bed speed and current on the machining time and MRR. They had used tool steel as work-material and brass wire (having diameter $0.18 \mathrm{~mm}$ ) as tool electrode material. The outcome of the study prevails the information regarding the optimum setting of input parameters under the given set of conditions. Nagaraja et al (2015) had presented a work in the field of optimization of input parameters for WEDM process. The main aim of this study was to find out the optimum values of cutting parameters to achieve the better surface finish and high rate of material removal. During the study, they had considered the three input parameters viz. pulse on time, feed rate of wire and pulse off time. They used Taguchi method for optimization of process parameters. At last of their study, they had concluded that all the three parameters are highly

significant factors. They also conclude that out of three input parameters, the feed rate of wire is more significant to attain the better surface roughness.

\section{EXPERIMENTAL SET-UP}

WEDM Machine: The experiments were carried out on a wire-cut EDM machine (ELEKTRA SPRINTCUT 734) of Electronica Machine Tools Ltd. installed at Central Tool Room (CTR), Ludhiana, Punjab, India. The WEDM machine tool has the following specifications: 
TABLE I. Specifications of Machine Tool

\begin{tabular}{|l|l|}
\hline Parameter & Specification \\
\hline Design & Fixed column, moving table \\
\hline Table size & $440 \mathrm{~mm}$ x $650 \mathrm{~mm}$ \\
\hline Maximum work-piece height & $210 \mathrm{~mm}$ \\
\hline Maximum work-piece weight & $510 \mathrm{~kg}$ \\
\hline Main table traverse $(\mathrm{X}, \mathrm{Y})$ & $300 \mathrm{~mm}, 400 \mathrm{~mm}$ \\
\hline Auxiliary table traverse $(\mathrm{u}, \mathrm{v})$ & $80,80 \mathrm{~mm}$ \\
\hline Wire electrode diameter & $0.25 \mathrm{~mm}, 0.15 \mathrm{~mm}, 0.20 \mathrm{~mm}$ \\
\hline Controlled axes & $\begin{array}{l}\text { XY,U,V simultaneous / } \\
\text { independent }\end{array}$ \\
\hline Interpolation & Linear \& Circular \\
\hline
\end{tabular}

Work piece and Tool Material: The AISI D3 die steel plate of length $200 \mathrm{~mm}$, width $50 \mathrm{~mm}$ and thickness $20 \mathrm{~mm}$ size was used as a work piece material for the present experiments. AISI D3 material is mostly used in blanking dies, plastic moulds, shear blades, swaging dies and thread rolling dies.

TABLE II. Chemical Composition of D3 Work-Material

\begin{tabular}{|c|c|c|c|c|c|}
\hline Element & $\mathrm{C}$ & $\mathrm{Si}$ & $\mathrm{Mn}$ & $\mathrm{Cr}$ & $\mathrm{Fe}$ \\
\hline \%age & 2.05 & 0.25 & 0.30 & 11.5 & 87.95 \\
\hline
\end{tabular}

The workpiece used in this experiment was shown in figure 2. SPRINTCUT 734 (ELEKTRA) WEDM machine was used for the present experimentation. The brass wire having diameter $0.25 \mathrm{~mm}$ was used as wire electrode for the present experimentation.

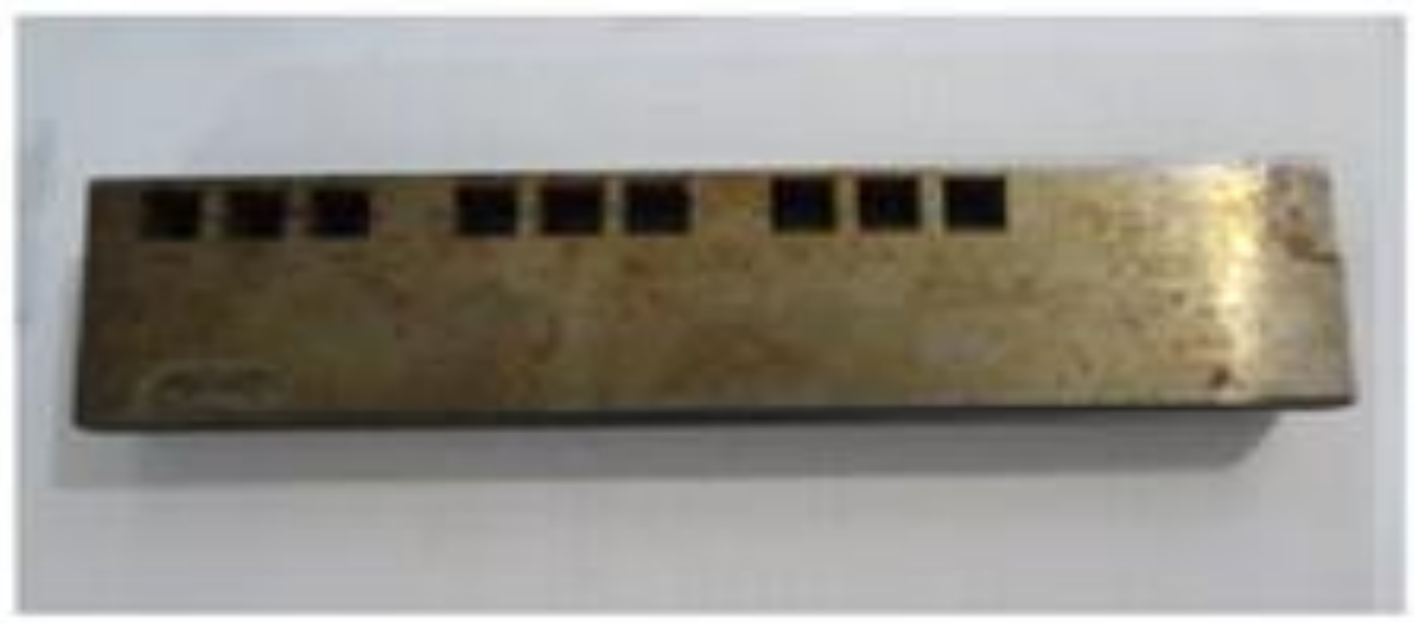

Fig. 2: photographic view of workpiece

Constant Input Parameters: During the experimentation, the various parameters were remain constant. The table 3 shows the description of these parameters and also shows their constant values. 
TABLE III. Constant Machine Parameters

\begin{tabular}{|c|c|}
\hline Parameter & Value \\
\hline Pulse-on- time & 115 units \\
\hline Pulse-off-time & 52 units \\
\hline Pressure of water & 10 units \\
\hline Feed rate of wire & $8 \mathrm{~m} /$ minute \\
\hline Wire-tension & 8 units \\
\hline Servo-voltage & 40 volt \\
\hline
\end{tabular}

\section{RESULTS AND DISCUSSION}

Measurement of Material Removal Rate: Experiments were performed keeping the selected input parameters constant. Table 4 shows results of cutting speed/cutting rate at various values of peak current.

TABLE IV. Results of Cutting Speed

\begin{tabular}{|c|c|c|}
\hline S.No. & Peak Current & $\begin{array}{c}\text { Cutting speed } \\
\text { (in } \mathrm{mm} / \mathrm{min} \text { ) }\end{array}$ \\
\hline 1 & 100 & 0.68 \\
\hline 2 & 170 & 0.76 \\
\hline 3 & 230 & 0.81 \\
\hline
\end{tabular}

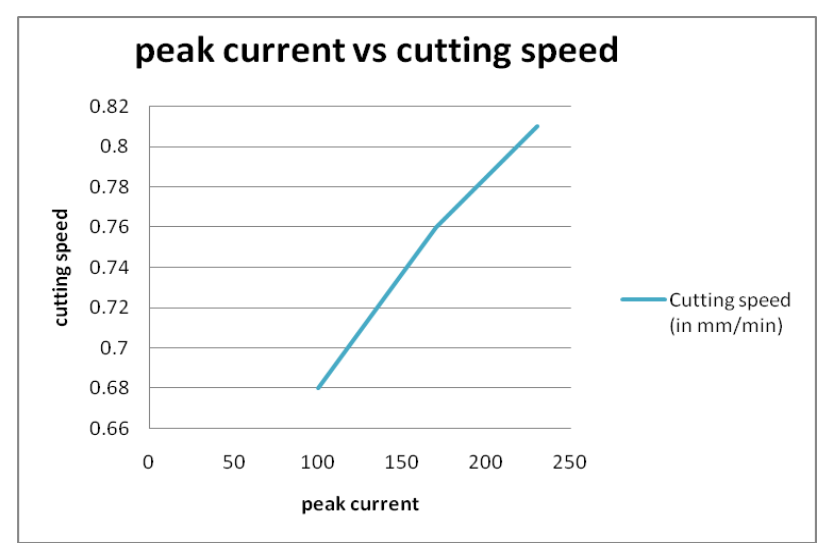

Fig. 3: Effect of peak current on Cutting Speed.

Figure 3 shows the significant increase in cutting speed/cutting rate with increase in peak current. This is because of the fact that with increase in the value of peak current, the energy/discharges gets enhances which leads towards increase in the cutting speed.

Measurement of Surface Roughness: Experiments were performed keeping the selected input parameters constant. Table 4 shows the results of surface roughness at various values of peak current. 
TABLE V. Results of Surface Roughness

\begin{tabular}{|c|c|c|}
\hline S.No. & Peak Current & $\begin{array}{c}\text { Surface Roughness } \\
\text { (in } \mu \mathrm{m} \text { ) }\end{array}$ \\
\hline 1 & 100 & 1.21 \\
\hline 2 & 170 & 1.25 \\
\hline 3 & 230 & 1.27 \\
\hline
\end{tabular}

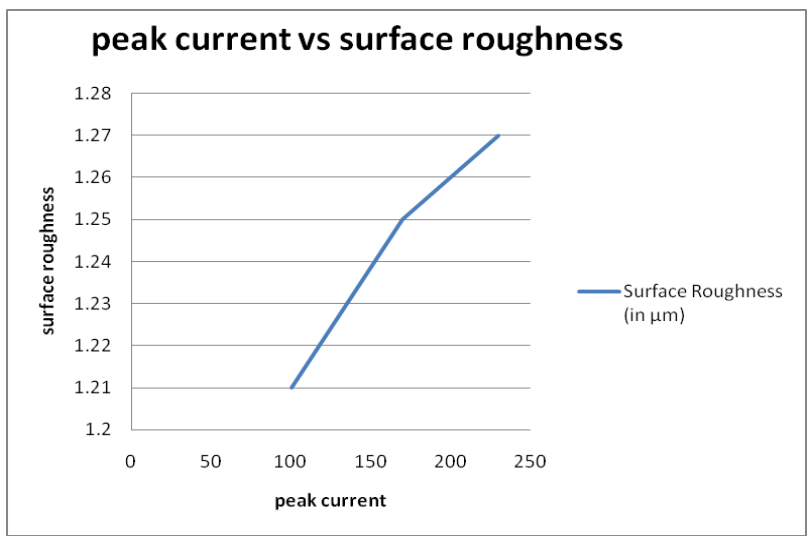

Fig. 4: Effect of peak current on surface roughness.

Figure 4 shows the significant increase in the magniture of surface roughness with increase in peak current. This is due to the fact that with increase in the peak current's value leads towards increase in the energy and due to this fact, the number of discharges gets increases and hence more material gets eroded from the surface of material.

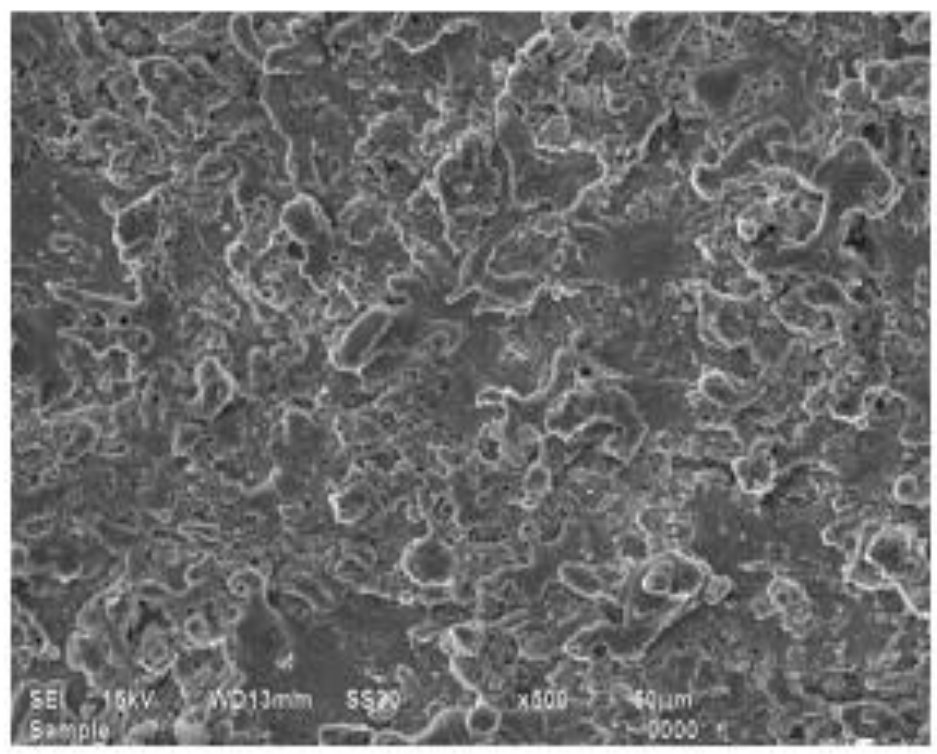

Fig. 5(a). SEM photograph showing microstructure of workpiece after machining with brass wire (at peak current of 100 units) 


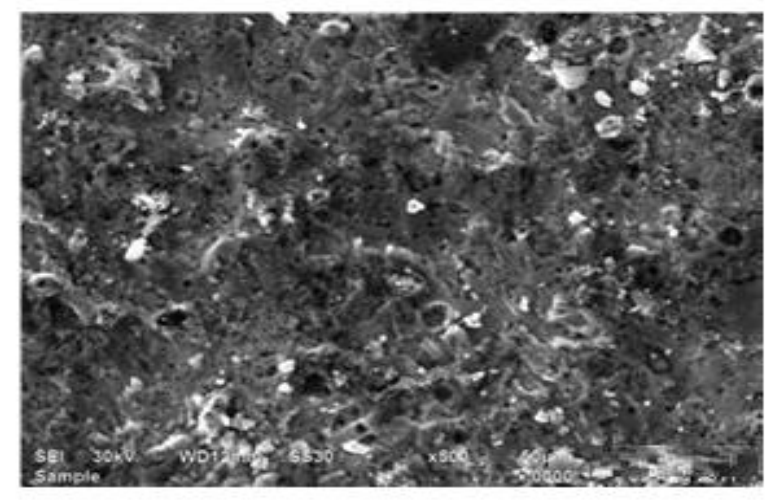

Fig. 5(b). SEM photograph showing microstructure of workpiece after machining with brass wire (at peak current of 170 units).

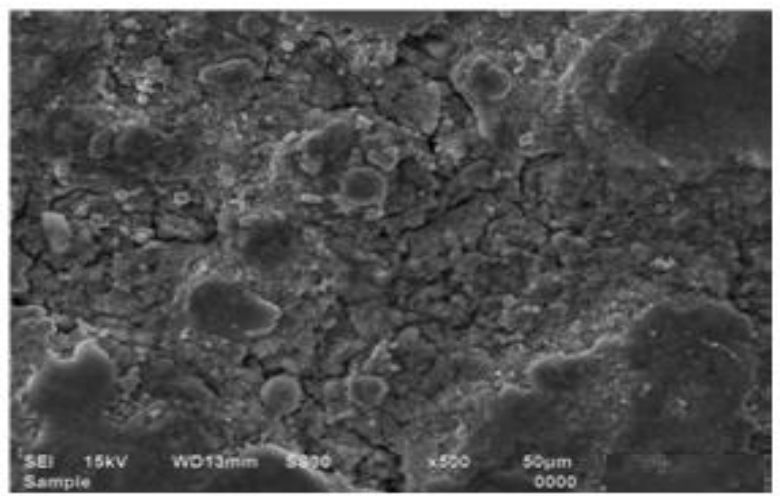

Fig. 5(c). SEM photograph showing microstructure of workpiece after machining with brass wire (at peak current of 230 units).

\section{CONCLUSION}

The results of the present study prevails the information that peak current significantly effect the performance parameters i.e. cutting speed/cutting rate and surface roughness. Higher the value of peak current, higher will be the cutting speed/cutting rate and surface roughness.

\section{REFERENCES}

[1] H. Ahmet, S. Ula and S. Çayda, "Experimental study of wire electrical discharge machining of AISI D5 tool steel", J Mater Process Technol 148,2004, 362-367.

[2] D. Scott, S. Boyina and K.P. Rajurkar, "Analysis and optimisation of parameter combination in wire electrical discharge machining", Int. J. Prod. Res., 1991, 2189-2207.

[3] S. Ebeid, R. Fahmy and S. Habib, "An Operating and Diagnostic Knowledge-Based System for Wire EDM", Springer Berlin/Heidelberg Publisher, 2003, 691-69.

[4] S. Saha, M. Pachon, A. Ghoshal, and M.J. Schulz, "Finite Element Modeling and Optimization to Prevent Wire Breakage in ElectroDischarge Machining", Mechanics Research Communications, 2004, 451-463.

[5] N. Tosun, C. Cogun, and G. Tosun, “ A Study on Kerf and Material Removal Rate in Wire Electrical Discharge Machining based on Taguchi Method”, Journal of Materials Processing Technology,2004, 316-322.

[6] J.L. Lin and C.L. Lin, "The use of Grey-Fuzzy Logic for the Optimization of the Manufacturing Process", Journal of Materials Processing Technology, 2005, 9-14.

[7] S. Sarkar, S. Mitra, and B. Bhattacharya, "Parametric Analysis and Optimization of Wire Electrical Discharge Machining of $\gamma$ titanium Aluminide Alloy", Journal of Materials Processing Technology, 2005, 286-294.

[8] S.S. Mahapatra, and A. Patnaik, "Optimization of Wire Electrical Discharge Machining (WEDM) Process Parameters using Taguchi Method”, International Journal of Advanced Manufacturing Technology,2 007, 911-925. 
[9] S.Datta and S.Mahapatra, "Modeling, Simulation and Parametric Optimization of Wire EDM Process using Response Surface Methodology Coupled with Grey-Taguchi Technique", International Journal of Engineering, Science and Technology, 2010, 162-183,

[10] R.Kumar and S.Singh, "Current Research Trends in Wire Electric Discharge Machining: An Overview", International Journal of Emerging Technologies, 2012, 33-40.

[11] A. Joshi, "Wire Cut EDM Process Limitations for Tool and Die Steel", International Journal of Technical Research and Applications, 2014, 65-68

[12] R. Nagaraja, K.Chandrasekaran and S.Shenbhgaraj, "Optimization of Parameter for Metal Matrix Composite in Wire EDM", Int. Journal of Engineering Science and Research Technology 2015, 570-574. 